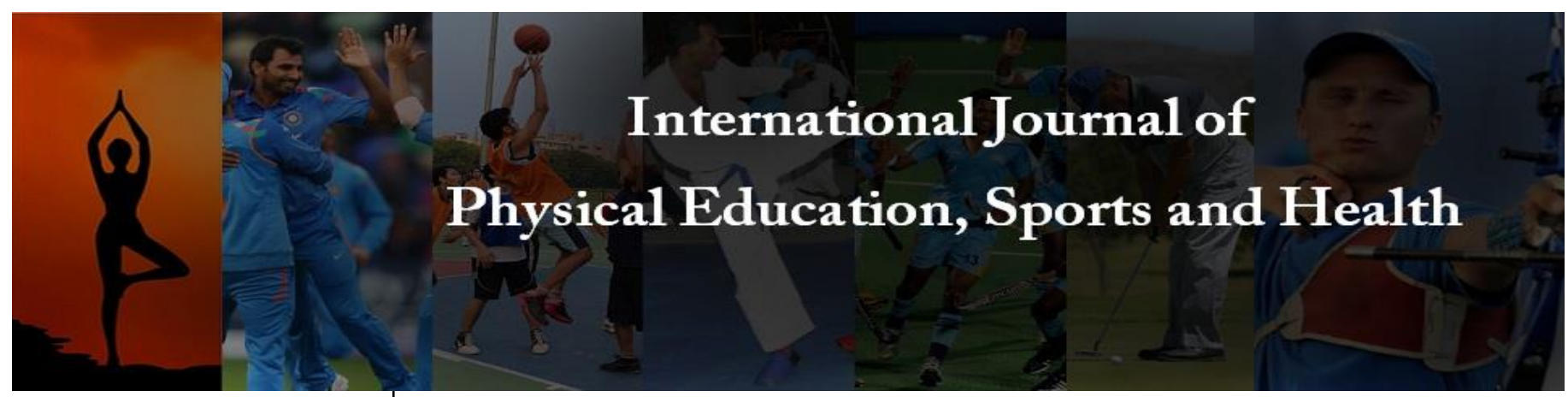

P-ISSN: 2394-1685

E-ISSN: 2394-1693

Impact Factor (ISRA): 5.38

IJPESH 2020; 7(5): 276-279

(C) 2020 IJPESH

www.kheljournal.com

Received: 04-05-2020

Accepted: 08-06-2020

\section{Sushanta Pal}

Assistant Professor, Government Physical Education College for women, Hooghly, West Bengal \& Research Scholar, Department of Physical Education, University of Kalyani, Kalyani, Nadia,

West Bengal, India

Dr. Susanta Sarkar

Associate Professor, Department of Physical Education,

University of Kalyani, Kalyani, Nadia, West Bengal, India
Corresponding Author: Sushanta Pal

Assistant Professor, Government Physical Education College for women, Hooghly, West Bengal \& Research Scholar, Department of Physical Education, University of Kalyani, Kalyani, Nadia, West Bengal, India

\section{Arm amplitude is the determinant factor for running between the wicket in cricket with equipment}

\author{
Sushanta Pal and Dr. Susanta Sarkar
}

DOI: https://doi.org/10.22271/kheljournal.2020.v7.i5e.1865

Abstract

The objective of the study was the particular technique adaptation made when performing running between the wicket in cricket in with equipment and without equipment condition. The twenty (20) male state level players were performed with and without equipment condition. A digital video graphic camera (Nikon D3300 with 60 FPS) were used for recording of motion. The subjects were performed in $30 \mathrm{~m}$ running in two different condition. The velocity was without equipment condition $3.53 \mathrm{~m} / \mathrm{s}$ at $2.5 \mathrm{~m}, 3.57 \mathrm{~m} / \mathrm{s}$ at $5 \mathrm{~m}, 4.66 \mathrm{~m} / \mathrm{s}$ at $10 \mathrm{~m}, 5.30 \mathrm{~m} / \mathrm{sat} 15 \mathrm{~m}, 5.51 \mathrm{~m} / \mathrm{sat} 22.5 \mathrm{~m}$ and $5.61 \mathrm{~m} / \mathrm{sat} 30 \mathrm{~m}$ position. With equipment condition was $3.43 \mathrm{~m} / \mathrm{s}$ at $2.5 \mathrm{~m}, 3.52 \mathrm{~m} / \mathrm{s}$ at $5 \mathrm{~m}, 4.44 \mathrm{~m} / \mathrm{sat} 10 \mathrm{~m}, 5.01 \mathrm{~m} / \mathrm{s}$ at $15 \mathrm{~m}, 5.20 \mathrm{~m} / \mathrm{sat}$ $22.5 \mathrm{~m}$, and $5.28 \mathrm{~m} / \mathrm{s}$ at $30 \mathrm{~m}$ position. i.e with constraint condition velocity was significantly decreased because one of the main linear kinematic parameter, arm amplitude was significant changed and it was the important technique. This study would help to guide clear direction for coaches and athletes.

Keywords: Arm amplitude, running between the wicket, velocity

\section{Introduction}

Running is a natural action for moving from one place to another place rapidly. A large number of investigations have been conducted to analyses the nature of running in the field of sports biomechanics. There may be situations where an individual requires to run in restraint condition may be due to physical injury or some congenital hindrance. At present Paralympics and other such International sports meets are organized to encourage participation of the physically challenged persons. There are a fairly large number of athletes to participate in them. But in the games and sports situation there are cases where a player requires to run in a constraint situation. A few research works have been completed for such cases. Cricket, one of the popular game where running between the wicket is the constraint situation. In Cricket main constraints are bat, pad, helmet. This constraint may reduce the velocity when a batsman runs in running between the wicket. In the point of biomechanics, the velocity may be reduced due changes of some kinematic factors. One of the main kinematic factors will be arm amplitude. Theoretically arm amplitude considered as the maximum anterior-posterior distance covered by two arms. While running with bat in running between the wicket it may change. generally, a cricket player holding a bat with both the hands when running, so the main hindrance may be bat.

\section{Methods}

Twenty state level male cricketer (Average age $=20.5$ years, average height $=167.6 \mathrm{~cm}$ and average weight $=56.3$ ) was considered for the present study. All Cricket players were selected from a cricket tournament organized by CAB, Kalyani, West Bengal. The players were performed $30 \mathrm{~m}$ running in without equipment and with equipment condition. Recording of the movement was completed in two times in the same day. Total running of both condition was recorded by the three video cameras (Nikon D 3300, 60FPS). The camera position and layout of the field was shown in the in the same time different running position's time also recorded. After capturing of video the recorded video was analyzed the movement analysis software (Kinovea 0.8.15) after kinematic analysis obtained data was analyzed through statistical procedure. 
Results

Table 1: Mean value of time and velocity without and with equipment condition of Cricket group of subject

\begin{tabular}{|c|c|c|c|c|c|c|}
\hline \multirow{2}{*}{$\begin{array}{c}\text { Distance } \\
(\mathbf{m})\end{array}$} & \multicolumn{3}{|c|}{ Time (s) } & \multicolumn{3}{c|}{ Velocity (m/s) } \\
\cline { 2 - 7 } & $\begin{array}{c}\text { Without } \\
\text { Equipment }\end{array}$ & $\begin{array}{c}\text { With } \\
\text { Equipment }\end{array}$ & $\begin{array}{c}\text { \% change of time with } \\
\text { equipment }\end{array}$ & $\begin{array}{c}\text { Without } \\
\text { Equipment }\end{array}$ & $\begin{array}{c}\text { With } \\
\text { Equipment }\end{array}$ & $\begin{array}{c}\text { \% change of velocity with } \\
\text { equipment }\end{array}$ \\
\hline 2.50 & 0.71 & 0.73 & 2.82 & 3.53 & 3.43 & -2.83 \\
\hline 5.00 & 1.40 & 1.51 & 7.86 & 3.57 & 3.32 & -7.00 \\
\hline 10.00 & 2.15 & 2.26 & 5.12 & 4.66 & 4.44 & -4.72 \\
\hline 15.00 & 2.84 & 3.0 & 5.63 & 5.30 & 5.01 & -5.47 \\
\hline 22.50 & 4.04 & 4.33 & 7.18 & 5.51 & 5.20 & -5.63 \\
\hline 30.00 & 5.36 & 5.69 & 6.16 & 5.61 & 5.28 & -5.88 \\
\hline
\end{tabular}

From the table values it is seen that the velocity for cricket group of subjects without and with equipment was increased, and rate of increase became gradually slower with increase of distance and time. However, it is evident from the above table values that the velocity without equipment remained from larger start and this difference gradually increased with respect to time and distance.

From the above table it is also seen that the percentage of time increased due to equipment for cricket group for running with equipment. Change in velocity (v) with respect to distance (s) for cricket group has been shown in the fig.1.

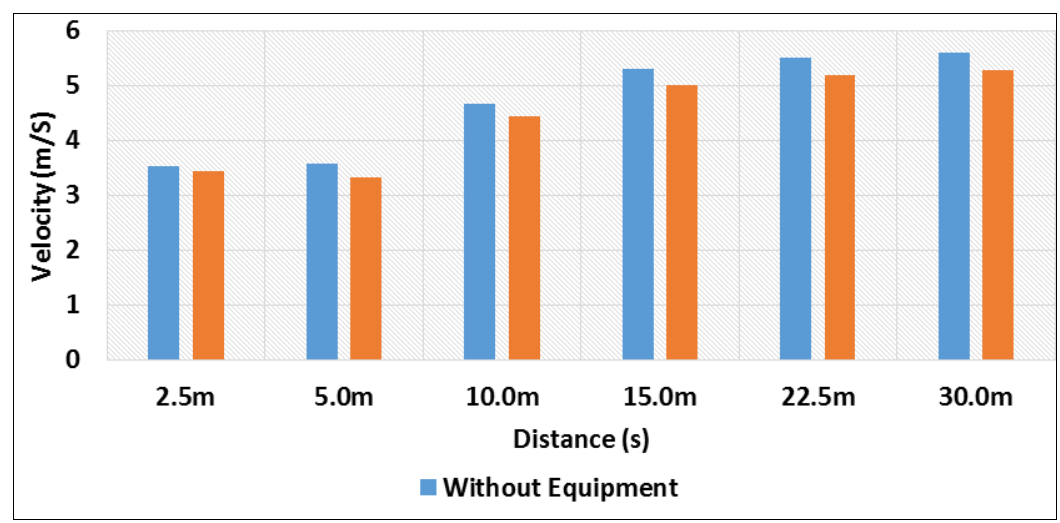

Fig 1: Velocity change with respect to distance for without and with equipment for cricket group of subject.

From the fig.-2 it is seen that the velocity was decreased with equipment condition of running in every position i.e $2.5 \mathrm{~m}$, $5.0 \mathrm{~m}, 10.0 \mathrm{~m}, 15.0 \mathrm{~m}, 22.5 \mathrm{~m}$ and $30.0 \mathrm{~m}$ position.
The percentage (\%) loss in velocity due to equipment for cricket group has been shown in fig.3.

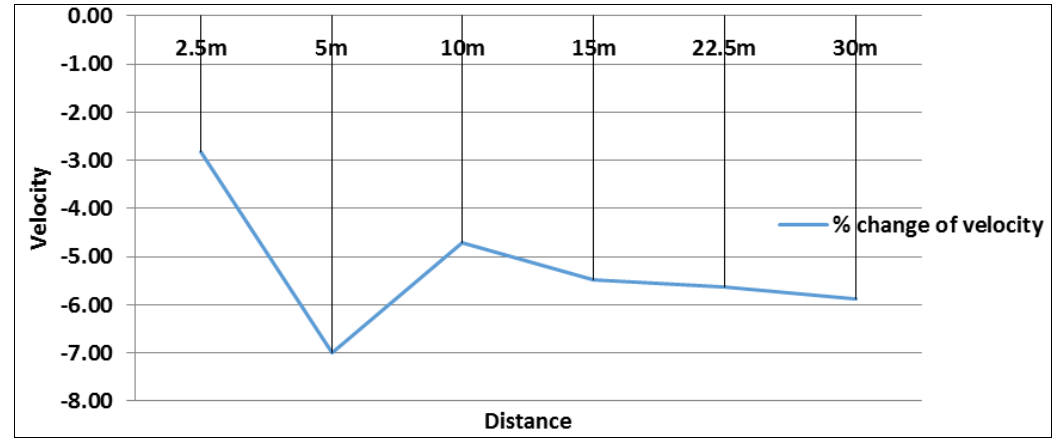

Fig 2: Percentage loss of velocity due to equipment for cricket group

After analyzing the change in velocity because of the constraint condition due to equipment, the other important selected linear kinematic parameter was analyzed. This was for understanding the cause of the change in basic kinematic parameter in running namely velocity by analyzing the arm amplitude.

Mean value of other important kinematic parameter without and with equipment for cricket group of subjects has been presented in table 2

Table 2: Mean value of arm amplitude for linear motion without and with equipment condition of cricket group of subjects

\begin{tabular}{|c|c|c|c|c|c|c|c|}
\hline \multicolumn{2}{|c|}{ Linear kinematic parameter } & \multicolumn{3}{|c|}{ Without equipment } & \multicolumn{3}{|c|}{ With equipment } \\
\hline & & $\mathbf{0 m}$ & $5 \mathrm{~m}$ & $15 \mathrm{~m}$ & $\mathbf{0 m}$ & $5 \mathrm{~m}$ & $15 \mathrm{~m}$ \\
\hline \multirow{3}{*}{ Arm amplitude (degree) } & Mean & 126.35 & 105.8 & 107.05 & 87.2 & 78.4 & 77.2 \\
\hline & S.D & \pm 17.80 & \pm 19.21 & \pm 16.44 & \pm 20.42 & \pm 14.06 & \pm 15.86 \\
\hline & Range & $98-179$ & $64-159$ & $70-152$ & $52-146$ & $59-107$ & $49-116$ \\
\hline
\end{tabular}


Table value indicates the mean value of arm amplitude without and with equipment condition in different selected position. It is very striking to note that the arm amplitude reduced drastically with equipment for all the three phases of running. This indicates that the condition of running with equipment created serious problems for adaptations during different phases of running.

This changes shown in the following fig.-2

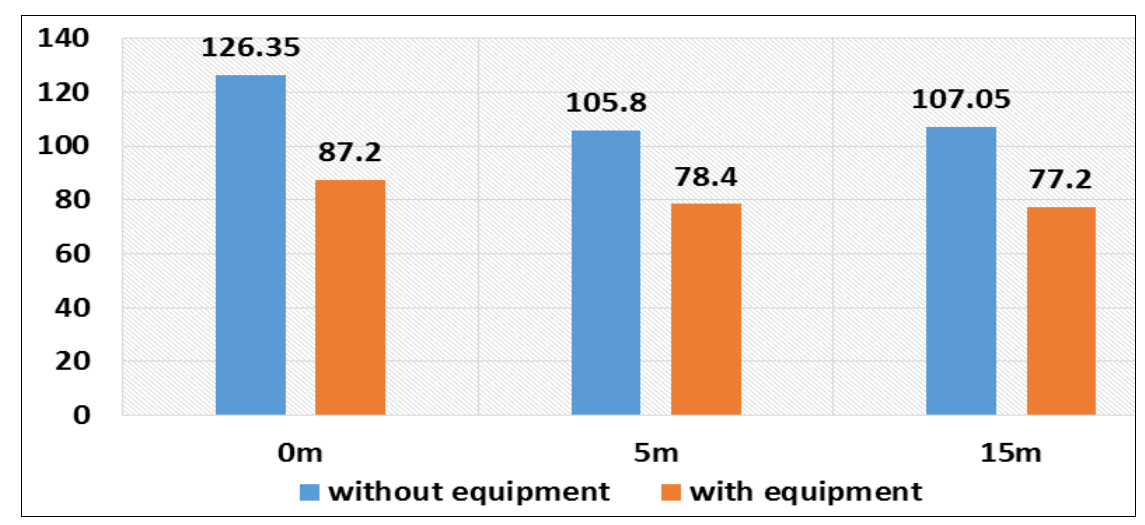

Fig 3: Arm amplitude without and with equipment condition

Fig.-4 it is seen that the value of arm amplitude for constraint condition was decreased for all three different position $(0 \mathrm{~m}$, $5 \mathrm{~m}$ and $15 \mathrm{~m}$ )

Testing of significant change in Arm Amplitude with equipment condition at $0 \mathrm{~m}$ was done by $\mathrm{t}$ test and the results have been shown in the following table 3 . It appears that the mean and S.D of without equipment condition were $126.35 \pm$
17.80 and the value with equipment condition were $87.2 \pm$ 20.42, Comparing the mean values of two different condition it was observed that there was difference in values exist. To observe that the significant difference between means $t$ was calculated and found to be 9.28 which was significant at 0.05 level.

Table 3: Represents the Arm Amplitude in without equipment condition and with equipment condition for cricket group at $0 \mathrm{~m}$ phase and their comparison

\begin{tabular}{|c|c|c|c|c|}
\hline & Without equipment condition & With equipment condition & t value & Remarks \\
\hline Mean(degree) & 126.35 & 87.2 & \multirow{2}{*}{9.28} & \multirow{2}{*}{ Difference between means was statistically significant } \\
\hline S.D & \pm 17.80 & \pm 20.42 & & \\
\hline
\end{tabular}

$\mathrm{df}=19, \mathrm{t}$ value at 0.05 level $=2.09$

Testing of significance of the different between mean values of Arm Amplitude without and with equipment revealed a statistically significant decrease in angle of Arm Amplitude at $0 \mathrm{~m}$ phase for with equipment condition at 0.05 level for cricket group of subject. Testing of significant change in Arm Amplitude due to equipment at $5 \mathrm{~m}$ was done by $\mathrm{t}$ test and the results have been shown in the following table 4 .
It appears that the mean and S.D of without equipment condition were $105.8 \pm 19.21$ and the value with equipment condition were $78.4 \pm 14.06$, Comparing the mean values of two different condition it was observed that there was difference in values exist. To observe that the significant difference between means $t$ was calculated and found to be 8.05 which was significant at 0.05 level.

Table 4: Represents the Arm Amplitude in without equipment condition and with equipment condition for cricket group at $5 \mathrm{~m}$ phase and their comparison

\begin{tabular}{|c|c|c|c|c|}
\hline & Without equipment condition & With equipment condition & t value & Remarks \\
\hline Mean(degree) & 105.8 & 78.4 & \multirow{2}{*}{8.05} & \multirow{2}{*}{ Difference between means was statistically significant } \\
\hline S.D & \pm 19.21 & \pm 14.06 & & \\
\hline
\end{tabular}

$\mathrm{df}=19, \mathrm{t}$ value at 0.05 level $=2.09$

Testing of significance of the different between mean values of Arm Amplitude without and with equipment revealed a statistically significant decrease in angle of Arm Amplitude at $5 \mathrm{~m}$ phase for with equipment condition at 0.05 level for cricket group of subject. Testing of significant change in Arm Amplitude due to equipment at $15 \mathrm{~m}$ was done by t test and the results have been shown in the following table 5. It appears that the mean and S.D of without equipment condition were $107.05 \pm 16.44$ and the value with equipment condition were $77.20 \pm 15.86$, Comparing the mean values of two different condition it was observed that there was difference in values exist. To observe that the significant difference between means $t$ was calculated and found to be 10.27 which was significant at 0.05 level.

Table 5: Represents the Arm Amplitude in without equipment condition and with equipment condition for cricket group at $15 \mathrm{~m}$ phase and their comparison

\begin{tabular}{|c|c|c|c|c|}
\hline & Without equipment condition & With equipment condition & t value & Remarks \\
\hline Mean(degree) & 107.05 & 77.2 & \multirow{2}{*}{10.27} & Difference between means was statistically significant \\
\hline S.D & \pm 16.44 & \pm 15.86 & & \\
\hline
\end{tabular}

$\mathrm{df}=19, \mathrm{t}$ value at 0.05 level $=2.09$ 
Testing of significance of the different between mean values of Arm Amplitude without and with equipment revealed a statistically significant decrease in angle of Arm Amplitude at $15 \mathrm{~m}$ phase for with equipment condition at 0.05 level for cricket group of subject.

Testing of significant change in Stride Length due to equipment at $0 \mathrm{~m}$ was done by t test and the results have been shown in the following table 28.

It appears that the mean and S.D of without equipment condition were $185.75 \pm 24.43$ and the value with equipment condition were $186.31 \pm 22.08$, Comparing the mean values of two different condition it was observed that there was difference in values exist. To observe that the significant difference between means $t$ was calculated and found to be 0.18 which was not significant at 0.05 level.

The results also indicated that there was significantly lower of arm amplitude during running for cricket group with equipment condition. While during running the bat was held in both the hands in cricket. This produced an unfavorable condition for shoulder movement for cricket group of subject for running.

\section{Conclusion}

The imposed constraint holding a bat and wearing pad, helmet may elicit a reduce in running speed performance. When compared without and with equipment condition running. Technique adaptation for arm amplitude, the value of arm amplitude was significant reduced in with equipment condition. This type of work may improve the specific training for the cricketers and the coaches and similarly in the sports field and helps to develop the performance.

\section{References}

1. Barrow HM, McGee R. A practical approach to measurement in physical education (Third ed.). Philadelphia: Lea \& Fibiger, 1979.

2. Coronin j, Hansen K, Kawamori N, Mcnair P.. Effects of weighted vests and sled towing on sprint. (R. t. group, Ed.) Sports Biomechanics, 2008, 160-172. doi:DOI: 10.1080/14763140701841381

3. Garrett HE. Statistics In Psychology \& Education. New Delhi: Paragon International Publishers, 2005.

4. Hall SJ. Basic Biomechanics (6th ed.). New York: McGraw-Hill, 2011.

5. Hay JG. The Biomechanics of Sports Techniques (4th ed.). United States: Benjamin Cummings, 1993.

6. Hopkinson JL. Sprint start. Track and Field. Quarterly Riview. 1993; 93(1):14-14.

7. Kansal DK. Test and measurement in sports and physical education. New Delhi: DVS Publications, 1996.

8. Maximilian M, Wdowski MJ. Kinematic adaptations in sprint acceleration performances without and with the constraint of holding a field hockey stick. Sports Biomechanics, 2013, 1-11. doi:10.1080/14763141.2012.749507

9. Office of the APA Style. Publication Manual of the Americal Psychological Association (7th ed.). Washington DC: American Psychological Association, 2020.

10. Wdowski MM, Gittoes MJ. Kinematic adaptations in sprint acceleration performances without and with the constraint of holding a field hockey stick. Sports Biomechanics, 2012, 1-11. doi:10.1080/14763141.2012.749507. 